\title{
Mineralization of Hazardous Waste Landfill Leachate using Photo-Fenton Process
}

\author{
Pradeep Kumar Singa ${ }^{1}$, Mohamed Hasnain $\mathrm{Isa}^{1}$, Yeek-Chia $\mathrm{Ho}^{1}$, Jun-Wei $\mathrm{Lim}^{2}$ \\ ${ }^{1}$ Department of Civil \& Environmental Engineering, Universiti Teknologi PETRONAS, 32610 \\ Bandar Seri Iskandar, Malaysia \\ ${ }^{2}$ Department of Fundamental \& Applied Sciences, Universiti Teknologi PETRONAS, 32610 Bandar \\ Seri Iskandar, Malaysia
}

\begin{abstract}
This study was conducted to evaluate the COD removal efficiency of Photo-Fenton oxidation process. The reagents used in the Photo-Fenton process are catalyst $\mathrm{Fe}^{2+}$ and $\mathrm{H}_{2} \mathrm{O}_{2}$ as oxidizing agent. A $16 \mathrm{~W}$ UV lamp was used to carry out the experiments. All the experiments were performed in batch mode to investigate the influence of operating conditions viz., Fenton reagents dosage, molar ratio and reaction time. The maximum COD removal observed was $68 \%$ under optimum operating conditions. The operating conditions $\mathrm{H}_{2} \mathrm{O}_{2} / \mathrm{Fe}^{2+}$ molar ratio $=3$ and reaction time $=90$ minutes were found to optimum. The dosages of Fenton reagents i.e. hydrogen peroxide and $\mathrm{Fe}^{2+}$ were optimum at $0.09 \mathrm{~mol} / \mathrm{L}$ and $0.03 \mathrm{~mol} / \mathrm{L}$ respectively.
\end{abstract}

\section{Introduction}

There is enormous generation of by-products due to the economic development and change in lifestyle. It's high time to address the problems related to generation of solid waste which ultimately ends up in landfills. Landfilling is the widely adopted waste disposal method around the world [1]. This method of waste disposal gives rise to highly toxic wastewater known as leachate, which is a result of degradation of organic matter mixing with rainwater [2]. The COD to BOD ratio is usually higher in leachate with low biodegradability mostly due to the presence of huge amount of recalcitrant aromatic compounds [3].

The characteristics of leachate vary with the landfill age, site hydrology, landfill depth, temperature, moisture content and composition of refuse. Leachate characteristics and the type and the quantity of chemical reagents used in the treatment method are the major factors affecting the performance of the treatment method. Many researchers have reported the hazardous potential of leachate. Hence, an efficient leachate treatment method is quite essential. Biological treatment methods are effective in the treatment of young leachate with a higher BOD/COD ratio. However they are not efficient in the treatment of mature leachate with high concentrations of recalcitrant compounds [4]. Nevertheless the hydroxyl ions generated by AOPs can oxidize the recalcitrant compound present in the landfill leachate [5]. Primo et al. [6] conducted experiments to investigate the effectiveness of

\footnotetext{
* Corresponding author: pmsinga@gmail.com
} 
various AOPs in the treatment of leachate. They reported that hydrogen peroxide alone has negligible effect on the degradation whereas the COD removal efficiency increased by $36 \%$ with the addition of UV irradiation in to the system. Photo-Fenton method decreased the COD by $80 \%$ within the reaction time of $60 \mathrm{~min}$. similar results were also obtained for TOC removal under the same system of study.

Contradictorily, studies conducted by Hermosilla et al.[5] Showed that Photo-Fenton has not much contribution to COD or TOC removal in comparison with Fenton process. It may be due to the fact that the turbidity inhibits the penetration of Ultra-Violet light into the sample and reduces the process efficiency. Nevertheless Photo-Fenton method has advantages viz; low catalyst consumption and low sludge production as compared to the conventional Fenton oxidation process. For effective treatment of effluents containing recalcitrant compounds, the scope must include both degradation and mineralization of organic pollutants, i.e. conversion of molecules to simple compounds: water and carbon dioxide. Advanced oxidation processes produce powerful active radicals at ambient temperature and pressure for degradation of contaminants. In water or wastewater treatment, AOPs include Fenton and its combinations such as Photo-Fenton, E-Fenton, $\mathrm{UV} / \mathrm{H}_{2} \mathrm{O}_{2}$, and $\mathrm{O}_{3} / \mathrm{UV}$. It has been reported by many researchers that AOPs have been used for degradation of COD, recalcitrant organic compounds, micro pollutants and also colour and odour removal [7]. Literature reports that AOPs are generally used for high strength organic wastewaters. The photo-Fenton process is one of the widely adopted methods to this group of wastewaters. Also it has been reported that Photo-Fenton method is successfully adopted for removal of recalcitrant compounds from various types of wastewaters or in combination with biological technologies [8].

\subsection{Fenton and Photo-Fenton based reactions}

In the conventional Fenton process, $\mathrm{OH} \bullet$ are generated from reactions between $\mathrm{Fe}^{2+}$ ions and $\mathrm{H}_{2} \mathrm{O}_{2}$ [9] wherein $\mathrm{Fe}^{2+}$ acts as a catalyst.

$$
\mathrm{Fe}^{2+}+\mathrm{H}_{2} \mathrm{O}_{2} \rightarrow \mathrm{Fe}^{3+}+\mathrm{OH}^{-}+\mathrm{OH} \bullet
$$

$\mathrm{Fe}^{3+}$ is again converted to $\mathrm{Fe}^{2+}$

$$
\begin{aligned}
& \mathrm{H}_{2} \mathrm{O}_{2}+\mathrm{Fe}^{3+} \rightarrow \mathrm{Fe}^{2+}+\mathrm{HO}+\mathrm{H}^{+} \\
& \mathrm{Fe}^{2+}+\mathrm{OH} \bullet \rightarrow \mathrm{Fe}^{3+}+\mathrm{OH}^{-}
\end{aligned}
$$

Degradation of organic matter takes place by hydroxyl radicals produced in the leachate:

$$
\begin{aligned}
& \mathrm{RH}+\mathrm{OH} \bullet \rightarrow \mathrm{H}_{2} \mathrm{O}+\mathrm{R} \bullet \\
& \mathrm{R} \bullet+\mathrm{Fe}^{3+} \rightarrow \mathrm{R}^{+}+\mathrm{Fe}^{2+}
\end{aligned}
$$

Adequate ferrous ions are necessary to maintain the moderate hydroxyl radical's reduction. But then again it generates enormous amount of sludge during the neutralization step which requires additional separation and disposal process. To increase the efficiency of the Fenton process, every experimental condition is optimized. This process is widely used in the treatment of various wastewaters including leachate due to its advantages i.e. easy operation, cost effectiveness, higher efficiency and no energy requirement. COD removal 
efficiency can be improved by combination of chemical and biological treatment methods [10].

Having mentioned the advantages, this process also has few disadvantages i.e. rapid utilization of ferrous ions with respect to its generation rate, sludge management and very narrow $\mathrm{pH}$ range. Photo-Fenton process overcomes these limitations and produces higher efficiency comparatively [11]. The main aim of this study was to investigate the optimum experimental conditions viz., $\mathrm{H}_{2} \mathrm{O}_{2} / \mathrm{Fe}^{2+}$ molar ratio, Photo-Fenton reagent dosages and reaction time in the removal of COD from hazardous waste landfill leachate.

Photo-Fenton process is improved version of Fenton process which uses Fenton reagents $\left(\mathrm{H}_{2} \mathrm{O}_{2}\right.$ and $\left.\mathrm{Fe}^{2+}\right)$ along with $\mathrm{UV}$-vis light $(\lambda<600 \mathrm{~nm})$ that produces extra $\mathrm{OH} \bullet$ radicals by set of reactions mentioned below. Eq. (6) and Eq.7 [12]:

$$
\begin{gathered}
\mathrm{Fe}(\mathrm{OH})^{2+}+h v \longrightarrow \mathrm{Fe}^{2+}+\mathrm{OH} \bullet, \quad \lambda<580 \mathrm{~nm} \\
\mathrm{H}_{2} \mathrm{O}_{2}+h v \longrightarrow 2 \mathrm{OH} \bullet, \lambda<310 \mathrm{~nm}
\end{gathered}
$$

The ferrous ions produced by UV light enter the Fenton reaction to produce extra hydroxyl radicals. Furthermore the photo-Fenton process has higher oxidation rate as compared to conventional Fenton process. Also there is enormous reduction in the consumption of iron and generation of sludge. In addition to that photo-Fenton process using UV light or solar light has given results in the killing of the microorganisms in polluted water bodies for potable or irrigation purpose [13].

\section{Methodology}

\subsection{Leachate sampling}

Leachate was sampled from locally available hazardous waste landfill. This facility receives around 100 tons of hazardous waste per day and the leachate generation is approximated to $150 \mathrm{~m}^{3} / \mathrm{d}$. leachate characteristics is as shown in Table 1 . The samples were transported to laboratory and stored in cold storage room at $4^{\circ} \mathrm{C}$ before being used for analysis. Measurement of all parameters was conducted in accordance with Standard Methods (APHA, AWWA, WEF, 2005).

Table 1. Characteristics of Landfill leachate

\begin{tabular}{|c|c|c|c|c|c|c|}
\hline Parameter & $\mathrm{COD}$ & $\mathrm{BOD}_{5}$ & $\mathrm{NH}_{3}-\mathrm{N}$ & Nitrates & $\begin{array}{c}\text { Suspended } \\
\text { solids }\end{array}$ & $\mathrm{pH}$ \\
\hline $\begin{array}{c}\text { Value } \\
(\mathrm{mg} / \mathrm{L})^{*}\end{array}$ & 4123 & 850 & 1557 & 22 & 1157 & 8.42 \\
\hline
\end{tabular}

*Except $\mathrm{pH}$ all other values are in $\mathrm{mg} / \mathrm{L}$

\subsection{Photo-Fenton experiments}

A series of experiments were carried out for Photo-Fenton oxidation process using the hazardous waste landfill leachate. The sample size employed was $500 \mathrm{ml}$. The sample stored in cold storage room was collected in a glass beaker and subjected to stirring for 30 
minutes to adjust the sample to room temperature. Once adjusted to room temperature the $\mathrm{pH}$ of the sample was adjusting to 3 using $1 \mathrm{M}$ sulphuric acid, as the acidic medium is the best suitable for Fenton oxidation process [14]. Calculated amounts of Fenton reagents were added to the sample under continuously stirring. A 16W UV lamp enclosed in a quartz tube was used in this experiment. To provide maximum light exposure to the sample, the UV lamp was immersed vertically in to the beaker containing the sample to the maximum possible depth leaving sufficient freeboard for the easy movement of the stirrer. The whole arrangement was covered with aluminum foil to avoid the contact with the UV light as shown in the Fig.1. After the completion of the experiment UV light was switched off first and aluminum foil was removed. The $\mathrm{pH}$ of the sample was increased to above 10 using $\mathrm{NaOH}$ to cease the reaction. Previous studies reported that at higher $\mathrm{pH}(\mathrm{pH}>10)$ values the degradation efficiency of organics via oxidation is terminated [7]. The sample was subjected to sedimentation for a period of $30 \mathrm{~min}$ after completion of the experiment and then supernatant was collected for analysis of COD.
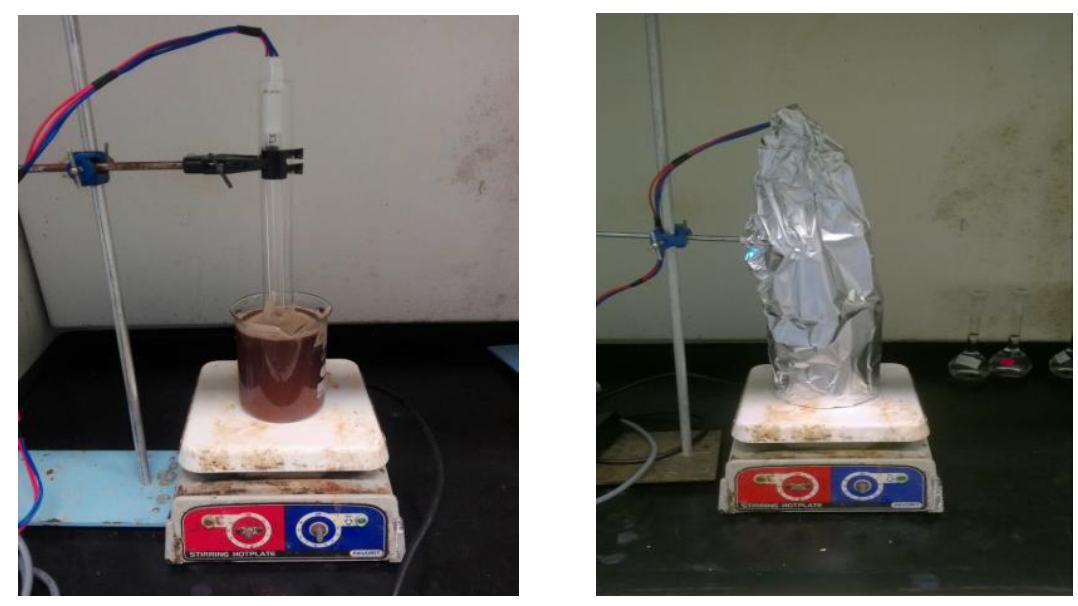

Fig.1. Experimental setup for Photo-Fenton process

\subsection{Analytical methods}

DR/5000 spectrophotometer was used to carry out the COD analysis. Distilled water was used in the preparation of all the required solutions. $\mathrm{pH}$ measurement was done using Hach $\mathrm{pH}$ meter. The experiments were performed in 3 replicates to achieve accuracy in the COD results. The Eq. 8 mentioned below was used to determine the COD removal percentage.

$$
R=\left(\frac{C o-C}{C o}\right) * 100
$$

$\mathrm{Co}=$ Initial COD and $\mathrm{C}=\mathrm{COD}$ post treatment. 


\section{Results and discussion}

\subsection{Molar ratio $\left(\mathrm{H}_{2} \mathrm{O}_{2} / \mathrm{Fe}^{2+}\right)$}

The efficiency and operation cost in Photo-Fenton oxidation process depends mainly on the concentrations of oxidizing reagent $\mathrm{H}_{2} \mathrm{O}_{2}$ and the catalyst $\mathrm{Fe}^{2+}$. In the Photo-Fenton process the two reagents hydrogen peroxide and ferrous sulphate play an important role in the oxidation of organic compounds. Combination of these two reagents generates powerful hydroxyl radicals which degrade the organic compounds.

The dosages of Fenton reagents is important in order to achieve higher efficiency, as excessive concentrations of these reagents results in scavenging of hydroxyl radicals leading to poor efficiency of the process. On the other hand low dosages of the reagents do not produce enough hydroxyl radicals to yield good results. Hence it becomes prerequisite to find the optimum ratios of these reagents to get higher efficiency. To determine the optimum $\mathrm{H}_{2} \mathrm{O}_{2} / \mathrm{Fe}^{2+}$ molar ratio, various $\mathrm{H}_{2} \mathrm{O}_{2} / \mathrm{Fe}^{2+}$ molar ratios i.e., 0.5, 1, 2, 3, 4 and 5 at $\mathrm{Fe}^{2+}$ dose of $0.01 \mathrm{~mol} / \mathrm{L}$ were experimented as can be seen in Fig.2. The Fig. 2 shows that the optimum molar ratio $\left(\mathrm{H}_{2} \mathrm{O}_{2} / \mathrm{Fe}^{2+}\right)$ is 3 attaining the highest COD removal of $54 \%$

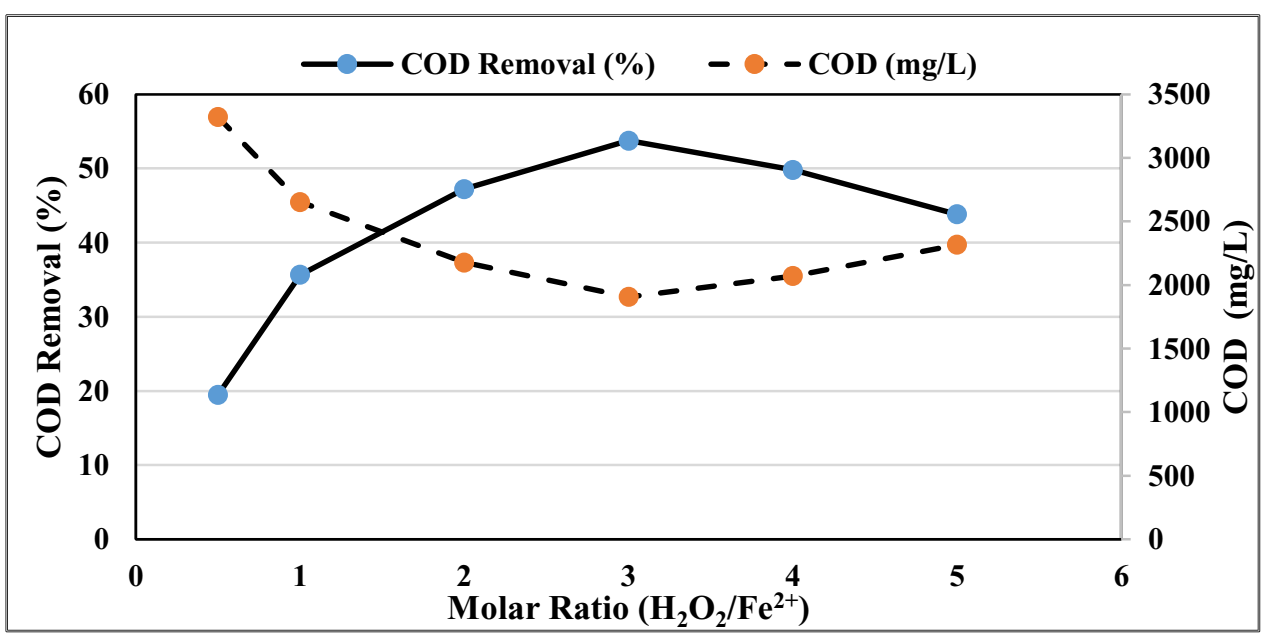

Fig. 2. Molar ratio vs COD removal $(\%)\left(\mathrm{Fe}^{2+}=0.01 \mathrm{~mol} / \mathrm{L}\right.$, Reaction time $\left.=60 \mathrm{~min}\right)$

It is important to note that the higher amounts of hydrogen peroxide results in break down to simpler molecules to form oxygen and water. Also the recombination of hydroxyl radicals leads to lowering of hydroxyl radical concentration which reduces the compound removal efficiency [15]. As it can be seen from the Fig.2 that the COD removal efficiency gradually decreasing after molar ratio 3 due to the scavenging effect of higher dosages of ferrous sulphate. Hence when a high amount of $\mathrm{Fe}^{2+}$ is available, $\mathrm{Fe}^{2+}$ and organic compounds compete to react with hydroxyl radicals. Thus, $\mathrm{Fe}^{2+}$ exhausts hydroxyl radical, resulting in to reduction of COD removal efficiency as depicted in Eq. 3.

\subsection{Fenton reagent dosage}

The major step in photo-Fenton process is to determine the optimum dosage of Fenton reagents $\left(\mathrm{H}_{2} \mathrm{O}_{2}\right.$ and $\left.\mathrm{Fe}^{2+}\right)$ due to their direct impact on the efficiency and operation cost. Higher concentrations of COD require higher dosage of hydrogen peroxide. At the same 
time, higher iron dosage leads to higher efficiency but excess dosages again contributes to higher TDS values, high sludge generation and scavenging effects [16]. Hence it is mandatory to determine the optimum dosages of both reagents to achieve higher efficiency with lower cost of operation.

To determine the optimum Photo-Fenton reagent dosages, a set of experiments were carried out keeping the molar ratio $\left(\mathrm{H}_{2} \mathrm{O}_{2} / \mathrm{Fe}^{2+}=3\right)$ and reaction time $(60 \mathrm{~min})$ constant and varying both the Fenton reagent dosages as shown in the Table 2. Fig 3 shows the effect of variation of Fenton reagent dosages on COD removal efficiency.

As can be seen from Fig.3, COD removal efficiency increased as Fenton dosages increased up to a certain point, beyond which the efficiency decreased due to scavenging effects of excess Fenton reagents available. Maximum COD removal attained is $63 \%$ with dosage of $0.09 \mathrm{~mol} / \mathrm{L}$ and $0.03 \mathrm{~mol} / \mathrm{L}$ of $\mathrm{H}_{2} \mathrm{O}_{2}$ and $\mathrm{Fe}^{2+}$ respectively.

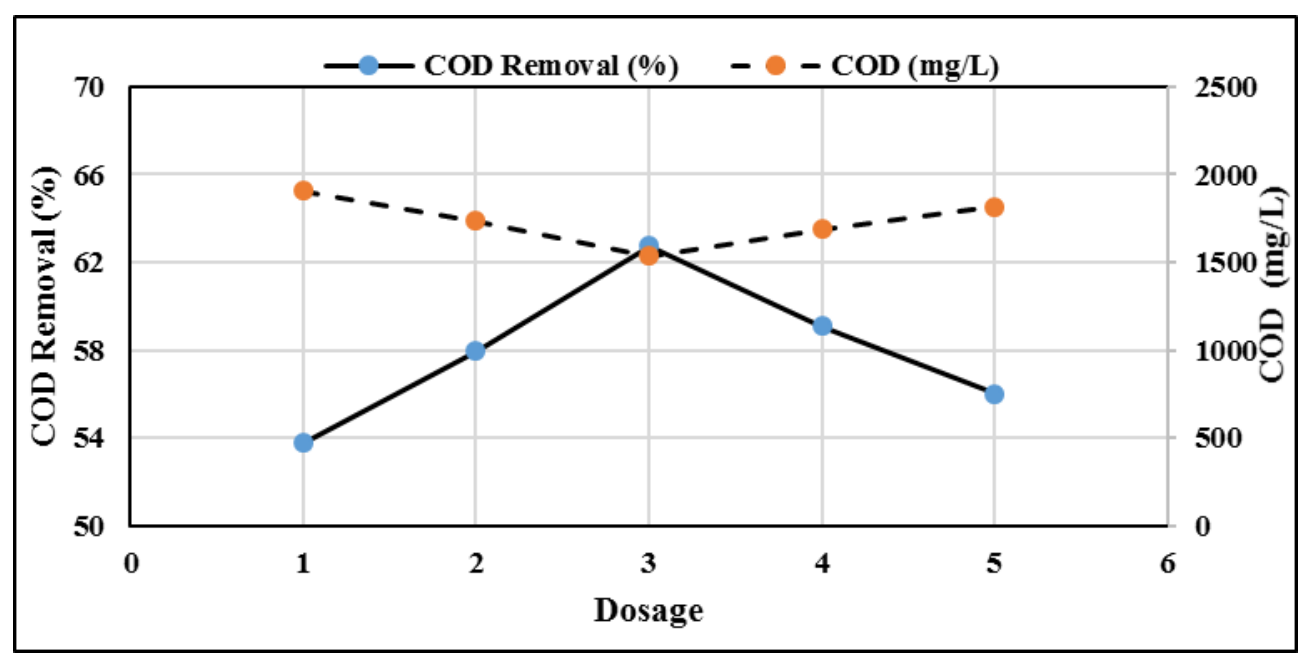

Fig. 3. Dosage of $\mathrm{H}_{2} \mathrm{O}_{2} / \mathrm{Fe}^{2+}$ vs COD removal (\%) (Molar ratio $=3$, Reaction time $\left.=60 \mathrm{~min}\right)$

Table 2. Fenton reagent dosages

\begin{tabular}{|c|c|c|c|c|c|}
\hline Dosage & 1 & 2 & 3 & 4 & 5 \\
\hline $\begin{array}{c}\mathrm{H}_{2} \mathrm{O}_{2} \\
(\mathrm{~mol} / \mathrm{L})\end{array}$ & 0.03 & 0.06 & 0.09 & 0.12 & 0.15 \\
\hline $\begin{array}{c}\mathrm{Fe}^{2+} \\
(\mathrm{mol} / \mathrm{L})\end{array}$ & 0.01 & 0.02 & 0.03 & 0.04 & 0.05 \\
\hline
\end{tabular}

\subsection{Reaction time}

Optimizing the reaction time is significant to attain higher efficiency in least possible time. Hence to optimize the reaction time for Photo-Fenton oxidation process, experiments were carried out by varying the reaction time. COD analysis was performed at an interval of every 30 minutes until 180 minutes. During this process the dosage of $\mathrm{H}_{2} \mathrm{O}_{2}$ and $\mathrm{Fe}^{2+}$ remained same for all the runs at $0.09 \mathrm{~mol} / \mathrm{L}$ and $0.03 \mathrm{~mol} / \mathrm{L}$, respectively. As can be seen 
from Fig.4 the maximum COD removal is $68 \%$ at 90 min duration. Increase in the reaction time beyond $90 \mathrm{~min}$ had no effect on the efficiency of the process.

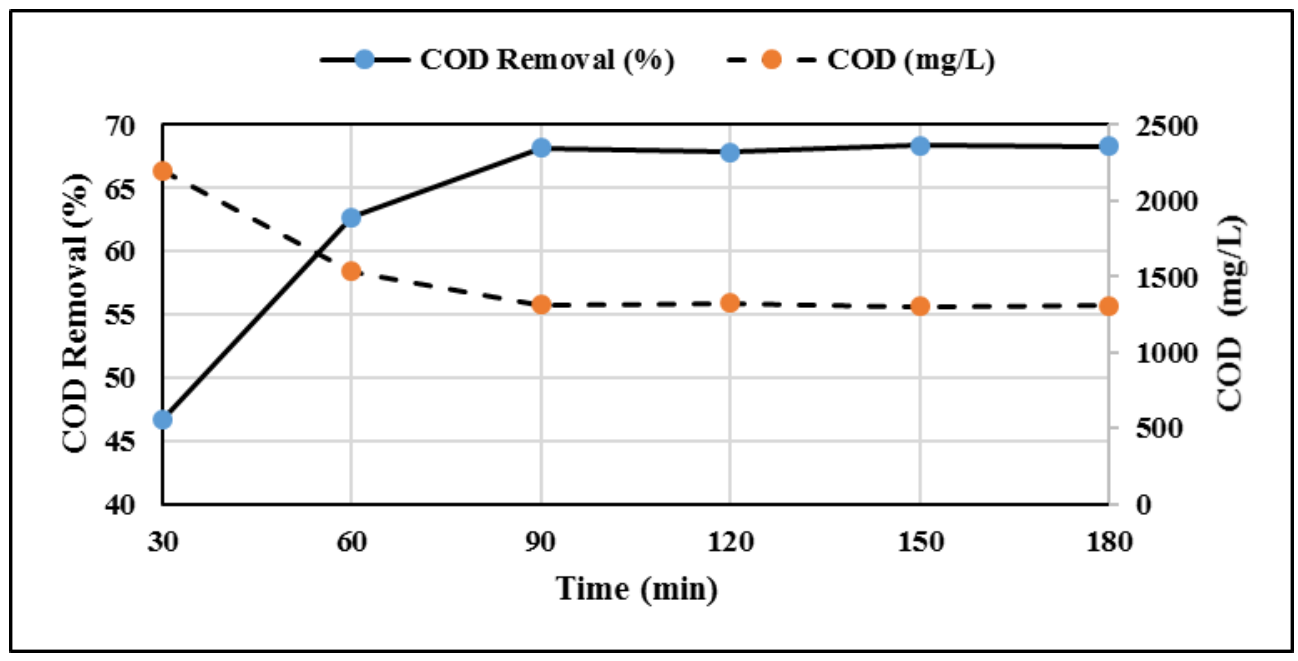

Fig. 4. Time vs COD removal (\%) $\left(\mathrm{H}_{2} \mathrm{O}_{2} / \mathrm{Fe}^{2+}=3, \mathrm{H}_{2} \mathrm{O}_{2}=0.09 \mathrm{~mol} / \mathrm{L}, \mathrm{Fe}^{2+}=0.03 \mathrm{~mol} / \mathrm{L}\right)$

\section{Conclusions}

Under the optimum operating conditions, the highest COD removal attained was $68 \%$. The optimized Photo-Fenton operating conditions were molar ratio $\left(\mathrm{H}_{2} \mathrm{O}_{2} / \mathrm{Fe}^{2+}\right)=3.0$ and reaction time $=90 \mathrm{~min}$. The optimum dosages of ferrous sulphate and hydrogen peroxide were $0.03 \mathrm{~mol} / \mathrm{L}$ and $0.09 \mathrm{~mol} / \mathrm{L}$ respectively. Hence it can be concluded that Photo-Fenton process is effective method for the treatment of hazardous waste landfill leachate in the removal of overall organic compounds.

\section{References}

1. T. A. Kurniawan, W. Lo, and G. Y. S. Chan, "Radicals-catalyzed oxidation reactions for degradation of recalcitrant compounds from landfill leachate," chem Eng Journal; vol. 125, pp. 35-57, (2006).

2. S. Renou, J. G. Givaudan, S. Poulain, F. Dirassouyan, and P. Moulin, "Landfill leachate treatment : Review and opportunity," Journal of hazardous materials; vol. 150, pp. 468-493, (2008).

3. Z. Salem, K. Hamouri, R. Djemaa, and K. Allia, "Evaluation of landfill leachate pollution and treatment, Desalination" vol. 220, pp. 108-114, (2008).

4. D. Robert and J. Surmacz-górska, "Landfill Leachate Treatment Methods: A Review,"Waste Management; no. April, (2006).

5. D. Hermosilla, M. Cortijo, and C. Pao, "Science of the Total Environment Optimizing the treatment of land fi 11 leachate by conventional Fenton and photoFenton processes," Sci. Total Environ., vol. 407, no. 11, pp. 3473-3481, (2009).

6. O. Primo, J. Rivero, and I. Ortiz, "Photo-Fenton process as an efficient alternative to the treatment of landfill leachates," Journal of hazardous material; vol. 153, pp. 834-842, (2008).

7. H. Zhang, H. Jin, and C. Huang, "Optimization of Fenton process for the treatment of landfill leachate," Waste Management; vol. 125, pp. 166-174, (2005). 
8. M. Umar, H. A. Aziz, and M. S. Yusoff, "Trends in the use of Fenton, electroFenton and photo-Fenton for the treatment of landfill leachate," Waste Manag., vol. 30, no. 11, pp. 2113-2121, (2010).

9. O. R. S. da Rocha, R. F. Dantas, M. M. M. Bezerra Duarte, M. M. Lima Duarte, and V. L. da Silva, "Solar photo-Fenton treatment of petroleum extraction wastewater," Desalin. Water Treat., vol. 51, no. 28-30, pp. 5785-5791, Aug. (2013).

10. P. Chen, K. G. Linden, D. E. Hinton, S. Kashiwada, E. J. Rosenfeldt, and S. W. Kullman, "Biological assessment of bisphenol A degradation in water following direct photolysis and UV advanced oxidation," vol. 65, pp. 1094-1102, (2006).

11. Y. Deng and J. D. Englehardt, "Treatment of landfill leachate by the Fenton process," Water Res., vol. 40, no. 20, pp. 3683-3694, (2006).

12. A. Marinas, J. M. Marinas, and F. J. Urbano, "Applied Catalysis B : Environmental A comparative study of photocatalytic degradation of 3-chloropyridine under UV and solar light by homogeneous ( photo-Fenton ) and heterogeneous ( $\mathrm{TiO} 2$ ) photocatalysis," "Applied Catal. B, Environ., vol. 127, pp. 316-322, (2012).

13. P. Karaolia, I. Michael, I. García-fernández, A. Agüera, S. Malato, P. Fernándezibáñez, and D. Fatta-kassinos, "Science of the Total Environment Reduction of clarithromycin and sulfamethoxazole-resistant Enterococcus by pilot-scale solardriven Fenton oxidation," Sci. Total Environ., vol. 468-469, pp. 19-27, (2014).

14. P. Taylor, "Influence of Fenton reagent oxidation on mineralization and decolorization of municipal landfill leachate,"Chemosphere; (2010).

15. S. K. Singh, W. Z. Tang, and G. Tachiev, "Fenton treatment of landfill leachate under different COD loading factors," Waste Manag., vol. 33, no. 10, pp. 21162122, (2013).

16. S. Sanchis, A. M. Polo, J. J. Rodriguez, and A. F. Mohedano, "Chemosphere Degradation of chlorophenoxy herbicides by coupled Fenton and biological oxidation," Chemosphere, vol. 93, no. 1, pp. 115-122, (2013). 